\title{
ANAESTHESIA FOR VENTRICULAR ANEURYSMECTOMY
}

\author{
F. Geonce Estafanous, ${ }^{*}$ F.F.A.R.C.s., Jomn F. VILjoen, ${ }^{\circ}$ F.F.A.R.C.s, \\ AND F.D. Loor, $\nmid$ M.D.
}

COFONARY ARTERY SURGERY HAS BEEN PERFORMED on more than 5000 patients at the Cleveland Clinic between January 1962 and June 1971, of which approximately 30 per cent were done in the last 18 months of this period. Patients undergoing ventricular aneurysmectomy presented special problems as evidenced by the high mortality (Table I) and morbidity encountered. We carefully evaluated the anaesthesia and postoperative management in 110 cases to improve, if possible, the overall care.

TABLE I

Hospital Mortality for Coronary Artery Surgery, 1/1970-6/1971

\begin{tabular}{lccccccc}
\hline & \multicolumn{2}{c}{ Myocardial Revascularization } & & \multicolumn{3}{c}{ Ventricular A neurysmectomy } \\
\cline { 2 - 4 } \cline { 5 - 8 } & Cases & Deaths & $\%$ Mortality & & Cases & Deaths & $\%$ Mortality \\
\hline 1970 & 1110 & 26 & 2.3 & & 80 & 8 & 10.0 \\
$1 / 1971-$ & 650 & 9 & 1.4 & & 52 & 3 & 5.8 \\
\hline
\end{tabular}

Pathology of a Ventricular Aneurysm

The diagnosis of a ventricular aneurysm is confirmed by coronary cineangiography and ventriculography. The usual cause of the aneurysm is occlusion of the anterior descending branch of the left coronary artery, producing a sizable scar in the anterior apical area of the left ventricle. Eventually the scar dilates, leading to formation of an aneurysm (Figure 1). Involvement of the diaphragmatic surface is rarely seen clinically since serious infarction in this region interferes with the mitral valve mechanism, ${ }^{1}$ greatly increasing early mortality.

\section{Basic Problems}

Coronary arteriosclerosis often affects more than one vessel and leads to partial or complete occlusion. The myocardium is dependent on collateral circulation which is frequently inadequate. For these reasons it was necessary to undertake combined revascularization procedures in 65 of our last 110 patients.

The autoregulatory mechanisms do not function properly in diseased vessels (vasodilatation in response to hypoxia does not occur to the same extent as seen with normal vessels). ${ }^{2}$ The haematocrit value is increased due to diuretic therapy which together with preoperative fluid restriction will increase the blood viscosity and may decrease myocardial perfusion. These factors result in diminishing availability of oxygen.

The area of the left ventricle involved by the aneurysmal dilatation has an altered

- Department of Cardiothoracic Anesthesia, The Cleveland Clinic Foundation.

tDepartment of Thoracic and Cardiovascular Surgery, The Cleveland Clinic Foundation.

Canad. Anaesth. Soc. J., vol. 19, no. 2, March 1972 


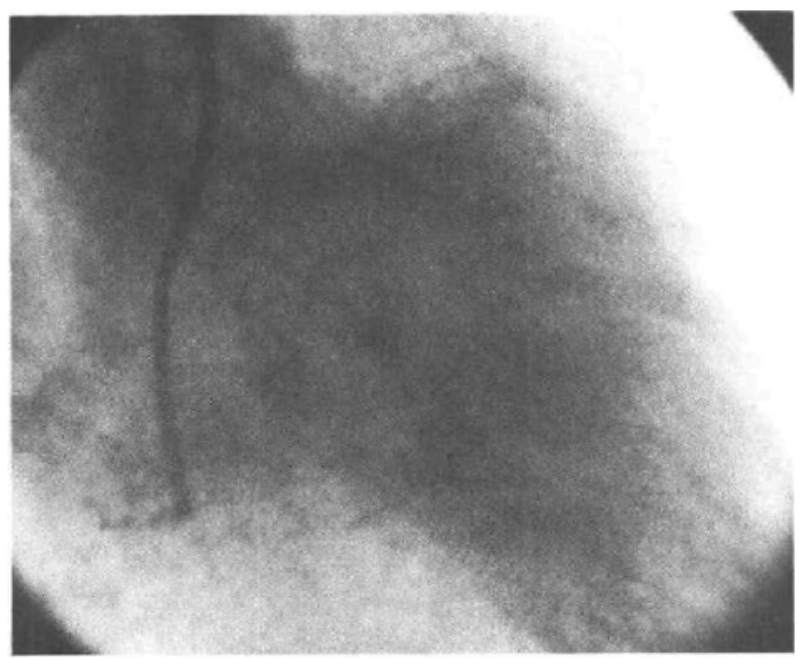

Figure 1

Ventricular aneurysm as shown by ventriculography.

compliance. This creates different expansile characteristics which interfere with coordinated myocardial contraction. ${ }^{*}$ Dilatation and deformation by the aneurysm increase the radius of curvature of the ventricle thas increasing myocardial systolic tension (Law of Laplace). "This along with the frequently encountered arrhythmias will increase oxygen consumption.

With each systolic contraction a part of the ejected volume will go to the aneurysmal sac instead of the aorta (resembling mitral regurgitation). That portion of blood which entered the aneurysm during systole returns to the ventricular cavity during diastole (resembling aortic regurgitation). 5 The functioning muscle is often affected by the ischaemic process and may be unable to compensate effectively. The cardiac output is decreased, left ventricular end-diastolic pressure is raised and congestive heart failure may occur.

\section{Preoperative Preparation}

The cardiologists fully investigate the patient's condition and prepare him so that he is in the best possible condition for surgery. Diuretic and digitalis therapy are discontinued 24 hours before surgery and $\beta$-adrenergic blockers, if used, are withdrawn at least 48 hours preoperatively.

A senior nurse conducts a class for all patients scheduled for surgery the following day. The environment of the intensive care unit is explained, and the importance of proper breathing, coughing, and the use of artificial breathing devices are explained.

The anaesthetist visits the patient the night before surgery for final evaluation and establishment of good rapport. A sedative is prescribed, e.g, pentobarbitone, $200 \mathrm{mg}$, to ensure a good night's sleep.

Papavaratum, $0.2 \mathrm{mg} / \mathrm{kg}$ body weight, and promethazine, $0.4 \mathrm{mg} / \mathrm{kg}$ body weight, are injected intramuscularly at least one hour preoperatively. 


\section{Management of Anaesthesia}

When the patient arrives in the quiet induction room, a $5 \mathrm{mg}$ tablet of isosorbide dinitrate is administered sublingually. The patient is made to breathe 100 per cent oxygen $\left(\mathrm{O}_{2}\right)$. Continuous monitoring of the electrocardiogram is established. The radial artery is cannulated ${ }^{b}$ under local anaesthesia with a 16-gauge angiocath connected to a simple aneroid manometer to monitor mean blood pressure. Anaesthesia is induced with 2 per cent thiopentone ( $3-4 \mathrm{mg} \mathrm{kg}$ ) followed by $30-40 \mathrm{mg}$ curare. These drugs are injected slowly while monitoring the mean blood pressure, considering the prolonged circulation time in these patients. The patient is ventilated manually by mask and air-way with 50 per cent nitrous oxide with oxygen to which an analgesic concentration of methoxyflurane ( $0.3-0.5$ per cent) is added.

The trachea is intubated when adequate muscle relaxation is achieved. After intubation, the internal jugular vein is cannulated percutaneously ${ }^{\top}$ and connected to a central venous pressure manometer. A nasogastric tube, a Foley catheter and a nasopharyngeal probe are introduced. Anaesthesia is maintained with nitrous oxide and oxygen, and methoxyfurane $0.3-0.5$ per cent and, if necessary, incremental doses of curare $6-9 \mathrm{mg}$ are administered to ensure diaphragmatic quiescence.

Blood gases, $\mathrm{pH}$, and electrolytes are checked every half hour. Ventilation is controlled. The percentage of oxygen and volume and pattern of ventilation are adjusted to maintain a $\mathrm{PaCO}_{2}$ of about $35 \mathrm{~mm} \mathrm{Hg}$ and a $\mathrm{PaO}_{2}$ of approximately $150 \mathrm{~mm} \mathrm{Hg}$ (10-12 ml $/ \mathrm{kg}$ tidal volume and rates of $10-12$ per minute are usually satisfactory).

If the serum potassium level is less than $4.5 \mathrm{mEq} / \mathrm{L}$, the deficit is corrected by administering $4 \mathrm{mEq}$ of potassium as potassium chloride, diluted in $25 \mathrm{ml}$ over a period of five minutes, to be repeated until the deficit is corrected, as indicated by electrocardiogram and by serum levels.

Nitroglycerine $0.2-0.4 \mathrm{mg}(1-2 \mathrm{ml})$ of freshly prepared solution is injected intramuscularly or intravenously every half hour depending on the level and response of the mean blood pressure.

The lungs are kept inflated by 100 per cent oxygen at a pressure of $3-5 \mathrm{~mm} \mathrm{Hg}$ during cardiopulmonary bypass. The effects of the muscle relaxants are not reversed at the conclusion of operation and the patient is moved to the recovery room on continuous manual ventilation with oxygen.

\section{Maintenance of Blood Volume}

Blood loss is replaced by correlation of the calculated losses (by weighing sponges and measuring the amount lost by suction) with central venous pressure, mean blood pressure, and left atrial pressure values.

It is also important to replace the indirect acute blood loss into the tubing of the heart-lung machine before the onset of perfusion, to avoid reflex vasoconstriction. This loss has been found to be between 300 and $350 \mathrm{ml}$.

\section{Withdrawal from Cardiovascular Bypass}

When the surgical repair is complete, the artificial circulation is changed from total to partial cardiopulmonary bypass. Cardiac rhythm either returns spon- 
taneously or is restored by direct current defibrillation. Some time after return of cardiac rhythm, the arterial cannula and vena caval lines are occluded and the heart is allowed to maintain the circulation.

Poor cardiac function after bypass is attributed to:

(a) Impaired blood supply to the residual myocardium. This problem may be reduced by direct operative revascularization.

(b) The effect of cardiopulmonary bypass and anoxic arrest on $\mathrm{pH}$ and electrolyte levels.

(c) The possibility of the residual ventricular chamber being too small.

If after ensuring an adequate blood volume, a serum potassium level between 4.5 and $5 \mathrm{mEq} / \mathrm{L}$ and after correcting any abnormalities in $\mathrm{pH}$ and arterial blood gases the heart fails to maintain a reasonable mean blood pressure $(65 \mathrm{~mm} \mathrm{Hg}$ ), retum to partial bypass and/or drug therapy is considered according to the following criteria:

1. Poor myocardial contraction accompanied by a pulse rate below 100 per minute, high central venous pressure, high left atrial pressure and a low blood pressure are treated by the infusion of dilute isoproterenol (Isuprel ${ }^{19}$ ) (0.4 $\mathrm{mg} / 500 \mathrm{cc}$ ).

2. The above combination associated with tachycardia is an indication for administration of intravenous calcium gluconate or rapid digitalization. The choice is based on the electrocardiogram pattern, previous digitalization, and serum potassium levels. Up to $10 \mathrm{ml}$ of 100 per cent calcium gluconate $(1 \mathrm{gm})$ or $0.8 \mathrm{mg}$ of digoxin is slowly injected intravenously.

3. Should tachycardia, arrhythmia or tachyphylaxis develop from the use of isoproterenol, or if there is no satisfactory effect after the administration of calcium gluconate or digitalis, intravenous glucagon ( $5-10 \mathrm{mg}$ ) is given.

4. When there is no improvement after the above measures, an epinephrine drip in a dilution of $10 \mathrm{mg} / 500 \mathrm{ml}$ may be of value.

5. When poor cardiac funotion is accompanied by electrocardiographic signs of myocardial ischaemia, the presence of coronary artery spasm is a possibility. Nitroglycerine $0.2-0.4 \mathrm{mg}$ is slowly injected intravenously and may be repeated according to response.

6. Arrhythmias are specifically treated either by drug therapy or by electric conversion.

7. In case of delayed recovery, 500-1000 mg hydrocortisone is given by intravenous injection.

\section{Return to Partial Bypass}

Occasionally a further period of rest to the myocardium may be beneficial. In this case, the patient is returned to partial cardiopulmonary bypass until signs of recovery are apparent (a lower left heart pressure and higher mean blood pressure).

In a situation where the circulatory status is poor and there is an obvious indication for drug therapy, such as arrhythmia, bradycardia, or tachycardia, the patient is returned to partial bypass concurrent with drug therapy. This will provide circulatory support until the supportive drug has become effective. 


\section{Surgical Technique}

The aneurysm is approached through a median sternotomy. The pericardium is often adherent to the scar and total cardiopulmonary bypass should be instituted before attempting mobilization of the ventricle. Since thrombi are within the aneurysm in at least half the cases, the aorta is cross-clamped to prevent embolization during the initial dissection or at the time of the ventriculotomy. If the patient requires a revascularization operation as well, it is undertaken after the aneurysm has been excised. A left atrial catheter is inserted at the junction of the right superior pulmonary vein with the left atrium. Before closure of the chest, pacemaker wires are implanted into the ventricular muscle.

\section{Postoperative Care}

Ventilation is controlled overnight by a pressure cycled ventilator (Bennett PR2). The inspired gases are humidified to 100 per cent at $37^{\circ} \mathrm{C}$. by a "Cascade" humidifier. The minimal inspired percentage of oxygen which will provide $\mathrm{PaO}_{2}$ of $100 \mathrm{~mm} \mathrm{Hg}$ is administered. In the presence of pulmonary congestion, widespread atelectasis, increased airway resistance or decreased chest compliance, a volume preset ventilator (Emerson) is used.

If the alveo-arterial $\mathrm{PO}_{2}$ difference is high, ${ }^{8}$ a positive expiratory pressure plateau is applied by connecting a resistance to the expiratory $\mathrm{limb}$ of the ventilator, to achieve an end-expiratory pressure to 5 to $10 \mathrm{~cm} \mathrm{H}_{2} \mathrm{O}$. Results of this have thus far been very encouraging."

The morning after the operation, arterial blood gases are measured and chest $\mathrm{x}$-rays are taken. If the results are acceptable the ventilator is adjusted to be triggered by the patient. Should the condition remain satisfactory for one-half hour, the trachea is extubated. Breathing and coughing exercises are started immediately and are repeated every two hours. Routine intermittent positive-pressure breathing (ten minutes every two hours) and chest physiotherapy (four times a day) are given during the first 48 hours. After this the need for continued ventilatory therapy is determined on an individual basis by the anaesthetist.

Blood volume is maintained by replacing normal physiological requirements and any blood lost through the chest drains. Furosemide (Lasix ${ }^{(9)}$ ) may be given if the urine output is less than $40 \mathrm{ml} /$ hour.

Any arrhythmias refractory to pacemaker control, or signs of cardiac failure, are specifically treated. Isosorbide dinitrate $2.5 \mathrm{mg}$ is administered sublingually every two hours for the first 24 hours, and thereafter in doses of $5 \mathrm{mg}$ every four hours. Potassium chloride is administered to maintain serum levels of potassium at $4.5-5 \mathrm{mEq} / \mathrm{L}$.

Adequate analgesia is provided by pantopon $0.3 \mathrm{mg} / \mathrm{kg}$ of body weight to be repeated according to the degree of consciousness and the degree of pain.

\section{Results}

One hundred and ten cases of ventricular aneurysmectomy were studied of which 104 were men and six were women. Their ages ranged from 37 to 69 years. 
TABLE II

Incidence of Use of Drug and Pump Support

\begin{tabular}{ccccccc}
\hline Pump & $\begin{array}{c}\text { Drug } \\
\text { Support }\end{array}$ & $\begin{array}{c}\text { Pump and } \\
\text { Drug } \\
\text { Support }\end{array}$ & Isoproterenol & Glucagon & $\begin{array}{c}\text { Calcium } \\
\text { Gluconate }\end{array}$ & Digitalis \\
\hline 18 & 19 & 20 & 34 & 8 & 12 & 8 \\
\hline
\end{tabular}

Sixty-five of these patients had combined myocardial revascularization and aneurysmectomy. The left ventricular end-diastolic pressure was more than $20 \mathrm{~mm} \mathrm{Hg}$ in 44 patients and exceeded $30 \mathrm{~mm} \mathrm{Hg}$ in 17 of them. The average preinduction mean blood pressure was $90 \mathrm{~mm} \mathrm{Hg}$ and only one patient presented with high blood pressure (225/100).

During induction there was an average drop in mean blood pressure of $15 \mathrm{~mm} \mathrm{Hg}$. Any greater fall was corrected by tilting the table to a $15^{\circ}$ Trendelenburg position.

Four patients whose mean blood pressure was below $80 \mathrm{~mm} \mathrm{Hg}$ were considered very poor risks. Anaesthesia was induced in the operating room with provision made for the immediate institution of artificial circulatory support. To avoid the danger of hypotension, intravenous pancuronium $6 \mathrm{mg}$, was substituted for curare in these patients. No fall in arterial mean pressure was noted and the pulse rate was raised by an average of 15 per cent.

No serious arrhythmia of ventricular origin occurred during induction. Occasional premature ventricular contractions were recorded in four patients, sinus tachycardia over 100 per minute in two, and partial or complete heart block in four. These were treated effectively by an isoproterenol drip).

After removal of the pump support, 57 patients failed to achieve a mean blood pressure of $65 \mathrm{~mm} \mathrm{Hg}$. Supportive treatment was employed (Table II) either by returning to bypass or by drugs, or by a combination of both.

Return to partial bypass, with or without drug therapy, was necessary in 38 cases for periods varying from 15 to 65 minutes. Support was suspended every five minutes to assess cardiac function. The return to bypass treatment alone was effective in 18 cases, and was combined with drug therapy in 20 cases.

Pharmacological support alone was successful in 19 patients. Isoproterenol was administered in 34 cases and was continued for periods of 12 to 24 hours in seven of these. In eight cases glucagon was used.

Intravenous digitalis was administered to eight patients, and intravenous calcium glaconate was given to twelve. More than one drug was used for seven patients.

Injection of nitroglycerine provided dramatic improvement in three patients in whom poor cardiac function was accompanied by electrocardiographic signs of ischaemia.

It was impossible to restore any cardiac function in two patients. One had irreversible ventricular fibrillation, the other maintained asystole. After two hours of intensive drug and pump support they were pronounced dead.

\section{Postoperative Course}

Postoperative complications were not uncommon (Table III). 
TABLE III

Major Postoperative Complications

\begin{tabular}{cccccc}
\hline \hline Arrhythmia & $\begin{array}{c}\text { Congestive } \\
\text { Heart Failure }\end{array}$ & $\begin{array}{c}\text { Myocardial } \\
\text { Infarction }\end{array}$ & $\begin{array}{c}\text { Cerebral } \\
\text { Embolism }\end{array}$ & $\begin{array}{c}\text { Pulmonary } \\
\text { Enbolism }\end{array}$ & $\begin{array}{c}\text { Gastra-Intestinal } \\
\text { Bleeding }\end{array}$ \\
\hline 39 & 12 & 8 & 7 & 4 & 4 \\
\hline
\end{tabular}

TABLE IV

TYPES OF ARRHYTHMIAS

\begin{tabular}{|c|c|c|c|c|c|c|}
\hline Arrhythmias & $\begin{array}{l}\text { Premature } \\
\text { Ventricular } \\
\text { Contractions }\end{array}$ & $\begin{array}{l}\text { Auricular } \\
\text { Fibrillation }\end{array}$ & $\begin{array}{l}\text { Atrial- } \\
\text { Ventricular } \\
\text { Block }\end{array}$ & $\begin{array}{c}\text { Paroxysmal } \\
\text { Atrial } \\
\text { Tachycardia }\end{array}$ & $\begin{array}{r}\text { Ventricular } \\
\text { Tachycardia }\end{array}$ & $\begin{array}{l}\text { Ventricular } \\
\text { Fibrillation }\end{array}$ \\
\hline 39 & 21 & 17 & 1 & 1 & 4 & 5 \\
\hline
\end{tabular}

TABLE $V$

Causes of Death

\begin{tabular}{lccccc}
\hline \hline Total & $\begin{array}{c}\text { Ventricular } \\
\text { Fibrillation }\end{array}$ & $\begin{array}{c}\text { Myocardial } \\
\text { Infarction }\end{array}$ & $\begin{array}{c}\text { Cerebral } \\
\text { Embolism }\end{array}$ & Other & $\begin{array}{c}\text { No return of cardiac } \\
\text { function (patient } \\
\text { died on table) }\end{array}$ \\
\hline 10 & $\begin{array}{c}5 \\
\text { (1 on table) }\end{array}$ & 1 & 2 & 1 & 1 \\
\hline
\end{tabular}

Arrhythmias (Table IV) occurred in 39 patients. Episodes of atrial fibrillation occurred in 17 patients and in each an external pacemaker was connected to the previously inserted wires. Ventricular tachycardia and fibrillation occurred in nine patients, of whom six were successfully resuscitated and three died.

Cerebral emboli occurred in seven cases, two of which resulted in death. There were four instances of pulmonary embolism.

Myocardial infarctions occurred in eight patients and resulted in two deaths. Twelve patients developed congestive heart failure.

In 15 patients it was essential to continue artificial ventilatory support for more than 24 hours. In four cases (one cerebral embolism and three congestive heart failures) tracheostomy was performed and intermittent positive-pressure breathing was continued for periods of four to six days.

The total number of postoperative hospital deaths was ten (Table V).

\section{Discussion}

Preoperative digitalis therapy may increase the incidence of arrhythmia during and after operation. $\beta$-adrenergic blockade is undesirable, since it predisposes to hypotension and bradycardia during anaesthesia and renders a failing heart resistant to positive inotropic agents. ${ }^{10}$

Adequate preoperative medication reduces anxiety and lessens the likelihood of an anginal attack occurring prior to induction of anaesthesia.

Preoxygenation will increase the amount of oxygen dissolved in the plasma, pro- 
viding a small reserve for any unexpected period of hypoxia during induction and intubation.

Thiopentone provides a smooth induction despite some theoretical objections to its use. When injected slowly over one to two minutes, depression of the myocar. dium and circulation is minimal and it has an antiarrhythmic effect. Curare is the muscle relaxant presently used for intubation and maintenance. Severe hypotension is not common in the well-hydrated patient when the drug is injected slowly and the patient is not already deeply anaesthetized. Trials of pancuronium bromide suggest that it may be of value in a bad risk patient. We have used low concentrations of methoxyflurane in myocardial revascularization procedures for seven years, and have been satisfied with the results. ${ }^{11}$ In the concentrations described it is less depressing to the myocardium than halothane, ${ }^{12}$ and provides a more stable cardiac rhythm than other drugs. The slow postoperative desaturation confers prolonged analgesia and helps the patient to tolerate the endotracheal tube and to accept artificial ventilation. Nephrotoxicity has not been encountered in our experience.

Adequate oxygen saturation and normal acid-base status are essential for optimal myocardial function. Maintaining a $\mathrm{PaCO}_{2}$ of approximately $35 \mathrm{~mm} \mathrm{Hg}$ will avoid the vasoconstriction and reduction in cardiac output which accompany excessive hypocapnia. ${ }^{13}$ A fall in serum potassium level is expected, due to previous diuretic therapy, cardiopulmonary bypass, the use of mannitol and increased potassium excretion in the postoperative period. ${ }^{14}$ Maintenance of serum potassium between 4.5 and $5 \mathrm{mEq} / \mathrm{L}$ is mandatory if cardiac arrhythmias and digitalis toxicity are to be avoided.

Respiratory insufficiency is common after cardiac surgery. Haemolyzed blood may be deposited in the interstitial lung tissue and miliary atelectasis is common. If the perfusion time is prolonged, changes in alveolar surface tension and manifestations of post-perfusion lung syndrome may appear.

With congestive heart failure there is ventilation perfusion inequality, indicated by increased alveolar arterial $\mathrm{PO}_{2}$ difference. ${ }^{15}$ Chest infection is common.

A urine output of $40 \mathrm{ml} /$ hour will afford some protection against renal failure. This figure suggests good tissue perfusion during cardiopulmonary bypass. Mannitol is administered if the output falls below this figure.

Maintenance of normal body temperature reduces postoperative shivering which would raise oxygen consumption, increase the work load of the heart due to vasoconstriction and release acid metabolites into the circulation.

The left atrial pressure correlates closely with left ventricular end-diastolic pressure (provided the mitral valve is intact). Left atrial pressure values of $35 \mathrm{~cm}$ $\mathrm{H}_{2} \mathrm{O}$ or more are common in these patients (normal 10 to $15 \mathrm{~cm} \mathrm{H}_{2} \mathrm{O}$ ). A gradual decline of left atrial pressure in the first 24 postoperative hours is a favorable prognostic sign. Changes in the left atrial pressure induced by volume expansion and inotropic drugs may not be refected immediately by central venous pressure measurements. ${ }^{16}$

In recording central venous pressure and left atrial pressure in 50 cases of our series, it was observed that the curves did not always run parallel to each other, and the gradient between their values was higher than normal, especially in the early 


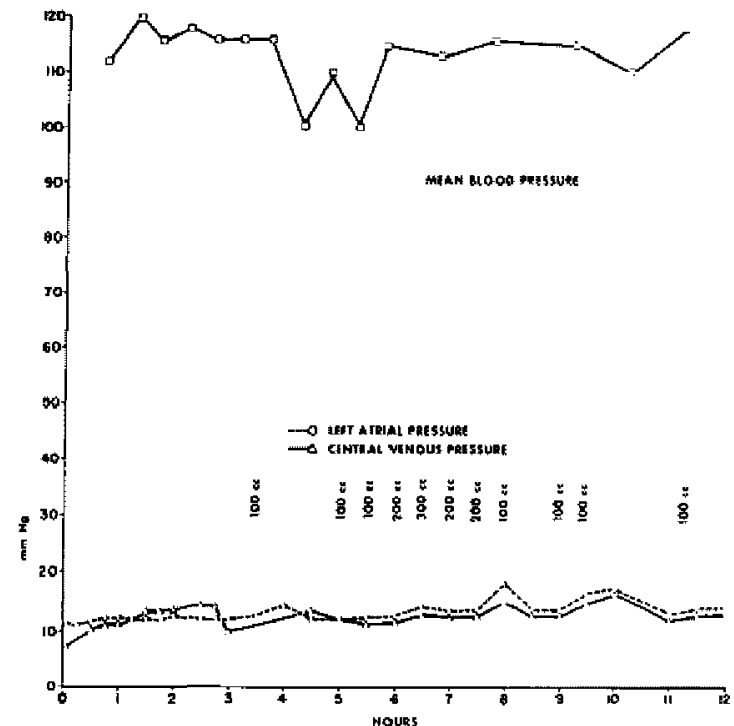

FIGURE 2

Satisfactory mean blood pressure values and a small gradient between the nearly parallel left atrial pressure and central venous pressure curves demonstrate an uneventful postoperative course.

postoperative period. It is important to use all the information available in evaluating circulatory status rather than placing too much emphasis on any one single measurement (see Figures 2 and 3 ).

Postoperatively the following syndromes may occur:

1. Low arterial mean pressure, low central venous pressure, and low left atrial pressure suggest blood volume deficit and are indications for transfusion.

2. Low arterial mean pressure, high left atrial pressure and high central venous pressure suggest low cardiac output based on myocardial failure and indicate inotropic drug therapy.

3. Low arterial mean pressure, high left atrial pressure and low central venous pressure once again indicate myocardial failure which has not been accompanied by central venous pressure rise, but obviously caution is advisable in transfusing these patients.

4. A high arterial mean pressure, low left atrial pressure and low central venous pressure indicate vasoconstriction and the need for peripheral vasodilators accompanied by cautious fluid therapy.

5. A small difference between rising central venous and left atrial pressures, together with a falling arterial mean pressure and increased mediastinal shadow on $x$-ray, would indicate cardiac tamponade.

Coronary vasodilators are administered in the following circumstances : ${ }^{17}$

1. Prior to the induction of anaesthesia to prevent angina occurring during preparation of the patient. 


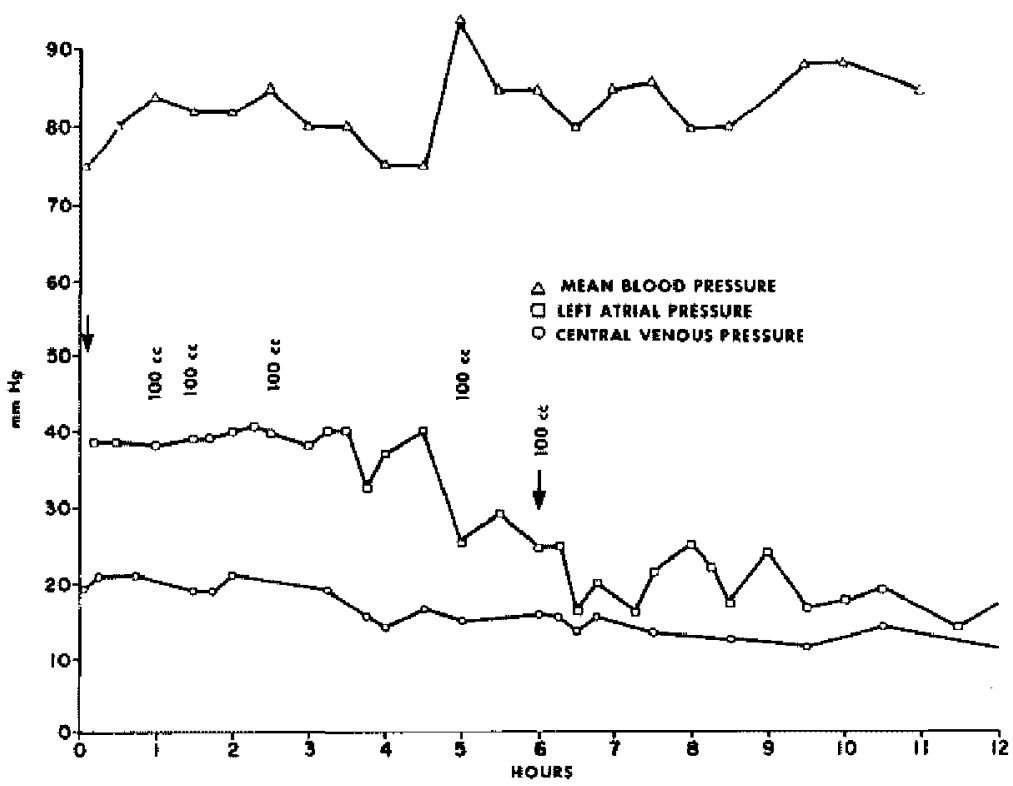

FIGURE 3

An unsatisfactory postoperative course necessitated administration of an isoprenaline drip for the first seven hours. A low mean blood pressure value and a high gradient between left atrial and central venous pressures are seen. After seven hours, improvement in the condition is evidenced by rising mean blood pressure, gradual decline of left atrial pressure and diminishing gradient between left atrial and central venous pressures.

2. During anaesthesia, ${ }^{18}$ to prevent reflex coronary vasoconstriction resulting from painful sensory input or direct manipulation of the heart.

3. While on cardiopulmonary bypass, to provide improved tissue perfusion and coronary vasodilatation.

4. Whenever changes in the s-T segment suggest myocardial ischaemia.

5. In the postoperative period when it is believed that coronary spasm may be a cause of myocardial infarction. ${ }^{19}$

The positive inotropic drug of choice is isoproterenol. This drug increases myocardial contractility as demonstrated by a reduction in left ventricular end-diastolic pressure. It has an immediate action and has been effective in our experience. If side effects such as tachycardia, arrhythmias or tachyphylaxis occur, the drug is discontinued.

Glucagon ${ }^{20}$ acts in a manner similar to isoproterenol and may be useful where digitalis toxicity is suspected and a cardiogenic drug is required. Unlike isoproterenol, glucagon does not lead to arrhythmia or tachycardia, especially in the digitalized patient. It has a somewhat longer duration of action, but clinically it has not been found as effective as isoproterenol. Maintenance of blood volume is a sine qua non when considering any drug therapy. 
Hydrocartisone ${ }^{21,22}$ is given on the basis that it enhances the pressor activity of circulating catecholamines, and delays cellular deterioration, so that normal cellular metabolism returns more quickly after restoration of adequate circulation.

The postoperative care is of critical importance. The simple monitoring systems described provide early and reliable warning of circulatory problems. The routine attachment of pacemaker wires in this group of patients facilitates immediate use of an external pacemaker to override refractory arrhythmias. Other arrhythmias are specifically treated.

Controlled postoperative ventilation is used overnight in all patients. The advantages are:

1. It confers some protection against pulmonary oedema - in many instances the left atrial pressure is still elevated.

2. It reduces cardiac work in a situation where adequate spontaneous respiration may be responsible for as much as 50 per cent of the total oxygen consumption. ${ }^{23}$

3. Having an endotracheal tube in situ enables more efficient resuscitation should this become necessary. Moreover, it minimizes anaesthetic problems, should reopening of the chest be required.

4. It maintains adequate ventilation when chest pain is most severe.

Weaning of the patient from ventilatory support should be done early in the day, when personnel and facilities are functioning at greatest efficiency.

\section{ConcLusion}

Important aspects in the anaesthetic and postoperative management of patients undergoing ventricular aneurysmectomy have been outlined. We believe that attention to the details described will decrease the overall mortality and morbidity associated with this procedure.

\section{SUMMARY}

Our technique of anaesthesia for resection of ventricular aneurysms is described. The haemodynamic changes which lead to decreased oxygen availability, increased oxygen consumption, and decreased cardiac output are kept in mind. Thiopentone, curare, and methoxyflurane are administered in doses which provide adequate anaesthesia and avoid myocardial irritability or depression. Careful attention is given to maintaining coronary dilatation and improving tissue perfusion by deliberate use of coronary vasodilators. Blood gases, $\mathrm{pH}$, and electrolytes, especially potassium $_{r}$ are monitored and maintained within normal limits, both during operation and postoperatively. Pharmacological support and retum to partial cardiopulmonary bypass employed when the heart function is inadequate, are also discussed. The importance of monitoring left atrial pressure and correlating it with central venous pressure and mean blood pressure is emphasized. Evaluation of the amount of transfusion, status of the myocardium, and the need for and the effectiveness of drug therapy are based on these observations. Postoperative arrhythmias are to be treated promptly and specifically. Prevention and management of postoperative respiratory complications are of the utmost importance. 


\section{ACKNOWLEDCEMENTS}

The authors gratefully acknowledge the assistance of Dr J.K. Potter, Chairman, Division of Anesthesiology, The Cleveland Clinic Foundation, and of Dr R.C. Tarazi, Research Division, The Cleveland Clinic Foundation.

\section{RÉSUMÉ}

Nous décrivons notre technique d'anesthésie au cours de la résection d'anéurysme du ventricule; il faut toujours avoir à l'esprit les changements de l'hémodynamique qu'entraînent une diminution de la quantité d'oxygène disponible, une augmentation de la consommation d'oxygène et une diminution du débit cardiaque. Nous donnons du thiopentone, du curare et du méthoxyflurane à des doses adéquates pour éviter la dépression et l'irritabilité du myocarde. Nous faisons bien attention pour maintenir une dilatation des coronaires et améliorer la perfusion des tissus en utilisant des vasodilatateurs des coronaires. Durant l'opération et au cours des suites opératoires, nous surveillons et maintenons dans les limites de la normale les gaz du sang artériel, le $\mathrm{PH}$ et les électrolytes, plus spécialement le potassium. Nous discutons également du support pharmacologique et du retour éventuel à la circulation cardiopulmonaire extra corporelle partielle lorsque le cœur ne peut remplir sa fonction. Nous insistons sur l'importance de surveiller la pression auriculaire gauche et de la tenir en correlation avec la pression veineuse centrale et la pression artérielle moyenne. C'est sur ces observations que nous basons la thérapie médicamenteuse, les quantités de sang à donner, l'état du myocarde et l'efficacité de la thérapie. L'arythmie post-opératoire fait l'objet d'un traitement précoce et spécifique. La prévention des complications respiratoires post-opératoires et leur traitement éventuel sont des plus importants.

\section{REFERENCES}

1. Efrter, D.B.; Westcott, R.N.; Groves, L.K.; \& Scull.y, N.M. Surgical Treatment of Ventricular Aneurysm. Arch. Starg., 87:249 (1963).

2. Wrnands, J.E.; Sheridan, C.A.; Batra, M.S.; Palmer, W.H.; \& Shanks, J. Coronary Artery Disease. Anesthesiology, 33:260 (1970).

3. Kelin, M.D.; Herman, M.V.; \& Gorlin, R. A Hemodynamic Study of Left Ventricular Aneurysm. Circulation, 35:014 (1967).

4. Bunton, A.C. The Importance of the Shape and Size of the Heart. Amer. Heart J., 54:801 (1957).

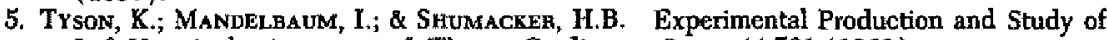
Left Ventricular Aneurysms. J. Thorac. Cardiovasc. Surg., 44:731 (1962).

6. Broww, A.E.; Sweney, D.B.; LumLex, J. Percutaneous Radial Artery Cannulation. Anaesthesia, 24:532 (1969)

7. Exclish, I.C.W.; FnEw, R.M.; PicotT, J.F.; \& Zakr, M. Percutaneous Catheterization of the Internal Jugular Vein. Anaesthesia, 24:521 (1969).

8. McIntyae, R.W.; Laws, A.K.; \& Ramachandran, P.R. Positive Expiratory Pressure Plateau Improved Gas Exchange During Mechanical Ventilation. Canad, Anaesth. Soc. J., $16: 477(1969)$

9. GINDr, M.Y. Personal Communication. (1971).

10. WARnER, W.A. Beta Adrenergic Blocking Agents and Anesthesia: A Review, Canad. Anaesth. Soc. J, 15:42 (1968). 
11. VIIJoEN, J.F. The Use of Methoxyflurane in Myocardial Revascularization Procedures. Det Anaesthesist, 19:22 (1970).

12. ReYNolds, A.K.; CHz, J.F; \& PAsQuet, A.F. Halothane and Methoxyflurane, A Comparison of Their Effects on Cardiac Pacemaker Fibers. Anesthesiology, 33:602 (1970).

13. Theye, R.A.; MrLDE, ].H.; \& Michenfelder, J.D. Elfect of Hypocapnia on Cardiac Output During Anesthesia. Anesthesiology, 27:778 ( 1966 ).

14. LockeY, E.; LONGMore, D.B.; Ross, D.N.; \& Sturaidge, M.F. Potassium and Open Heart Surgery. Lancet, $671(3 / 26 / 1966)$.

15. Hever, H.E.; Holman, J.; \& Smues, G.T. The Diminished Efficiency and Altered Dynamics of Respiration in Experimental Pulmonary Congestion. Amer. Heart J., 35:463 (1948).

16. Bels, H.; Stubrs, D.; \& Pugh, D. Reliability of Central Venous Pressure As An Indicator of Left Atrial Pressure. Diseases of the Chest, 59:169 (1971).

17. Rowe, G.G. Pharmacology of the Coronary Circulation. Ann. Rev. Pharmacol., 8:95 (I968).

18. ViLjoEN, J.F. Anesthesia for Internal Mammary Implant Surgery. Anaesthesia, 23:315 (1968).

19. Owhen, P.A. Coronary Attery Insufficiency. Diseases of the Chest, 44:561 (1963).

20. Wrlliams, J.F.; Childress, R.H.; Chip, J.N.; \& Border, J.F. Hemodynamic Effects of Glucagon in Patients with Heart Disease. Circulation, 39:38 (1969)

21. Dietzman, R.H. \& Lillemel, R.C. The Treatment of Cardiogenic Shock; the Use of Corticosteroids in the Treatment of Cardiogenic Shock. Amer. Heart J., 75:274 (1968).

22. Perzroth, M.G. \& Harrison, D.C. Cardiogenic Shock. Clin. Pharmacol. Therap, 10:499 (1969).

23. Dammann, J.F.; Thung, N.; Chistrieb, I.I; Littlefreld, J.B; \& Mullef, W.H. The Management of the Severely Ill Patient After Open Heart Surgery. J. Thorac. Cardiovasc. Surg., $45: 80$ (1963). 